\title{
UN MUSEO PARA UN ARTE SIN LÍMITES: MORI BUILDING DIGITAL ART MUSEUM
}

\section{A MUSEUM FOR AN UNLIMITED ART: \\ MORI BUILDING DIGITAL ART MUSEUM}

\author{
Diana María Espada Torres \\ Universidad de Zaragoza
}

Resumen Este artículo versa sobre la creación del primer museo de arte digital del mundo, inaugurado el 21 de junio de 2018 en Tokio (Japón). Nos referimos al Mori Building Digital Art Museum: teamLab Borderless, que se encuentra situado en la isla artificial de Odaiba, núcleo de la cultura futurista nipona y dominada por el edificio Fuji TV del arquitecto Kenzo Tange, el cual, a su vez, es sede del Miraikan, el Museo de la Ciencia y la Tecnología Emergentes de Japón.

Este lugar es perfecto para esta nueva disciplina artística que adquiere cada vez más notoriedad en la sociedad actual, por su capacidad de combinar manifestaciones artísticas con diferentes tipologías tecnológicas, produciendo de esta manera instalaciones inmersivas con un fuerte impacto en el espectador y que a su vez convierten a la tecnología en una inmensa obra de arte.

Palabras clave Arte Digital, Museo Digital, Siglo XXI, Japón, Arte, Tecnología, Ciencia, Creatividad.

Abstract This paper deals with the creation of the world's first digital art museum, inaugurated on 21 June 2018 in Tokyo (Japan). The Mori Building Digital Art Museum: teamLab Borderless is located on the artificial island of Odaiba, that is the heart of Japan's futuristic culture and is surrounded by architect Kenzo Tange's Fuji TV building, which in turn is the home of Japan's Miraikan, Japan's Museum of Emerging Science and Technology.

This place is perfect for the new artistic discipline that is becoming more and more notorious in today's society, for its ability to combine artistic manifestations with different technological typologies, thus producing immersive installations with a strong impact on the viewer and at the same time turning technology into an immense work of art.

Keywords Digital Art, Digital Museum, 21st Century, Japan, Art, Technology, Science, Creativity. 
Desde los inicios del siglo xxI, el progreso y el fuerte impacto de las nuevas tecnologías han originado una apresurada transformación a nivel global que ha ocasionado nuevas formas de acceso, consumo, difusión cultural y creación artística. Los usuarios y públicos culturales han ido adquiriendo mayor trascendencia, por lo que las distintas instituciones culturales como las museísticas, se han ido viendo obligadas a renovar sus estrategias para poder conectar con una sociedad cada vez más colaborativa y global. En cualquier caso, está claro que para el mundo de la cultura, la era digital no representa un futuro posible, sino que constituye una realidad presente.

Del mismo modo, si se considera la difusión cultural como la «trasferencia de conocimiento cuyo objetivo es permitir la accesibilidad del conjunto de la sociedad al uso y disfrute del patrimonio cultural» (Mateos Rusillo, 2013: 4), la labor del museo implica desarrollar campañas y acciones de índole comercial que susciten el interés y la consiguiente asistencia del público a sus exposiciones y actividades. Tradicionalmente, se ha trabajado con el empleo de catálogos, guías y maquetas, pero es indudable que la relación entre museos y tecnología es cada vez más estrecha. Por una parte, la tecnología está transformando el espacio mismo del museo; por otra, (en su concepción de herramienta) genera nuevas formas de creación artística. En consecuencia, estas dos modificaciones repercuten en la forma en que, ya sea como artistas o como visitantes, nos relacionamos con el contenido y con el continente, ya que se crean unos espacios sumamente dinámicos, en los que conviven las modalidades multimedia, crossmedia, transmedia, así como la realidad aumentada y la realidad virtual (Kulesz, 2014). Sin embargo, no debemos olvidar que los museos de arte han sido considerados, desde el siglo XVIII, como unas instituciones conservadoras, fuentes de cultura y de prestigio académico y social.
La evolución que ha experimentado la sociedad actual -cada vez más amplia y activa en los distintos procesos de gestión cultural que se van desarrollando-, junto con la mejora de los nuevos medios y soportes tecnológicos, ha permitido un discurso que está consiguiendo explotar al máximo estos nuevos recursos (Hooper Greenhill, 1998). Debemos pensar que lo digital no solo impacta en el acceso y difusión, sino también en las nuevas formas de concebir y crear. A día de hoy, algunos espacios museísticos ya no se limitan al espacio físico, sino que comenzamos a ver cómo, en algunos casos, el espacio arquitectónico y el virtual se complementan. Este es el caso del Mori Building Digital Art Museum: teamLab Borderless.

Fue en junio de 2018 cuando nació este primer museo digital, a escala real, del mundo. Se ubicó en el complejo Palette Town, en la isla de Odaiba, una extensa superficie artificial en la bahía de Tokio que en origen se edificó por motivos defensivos. El nombre de Odaiba proviene de una serie de seis fortalezas isleñas construidas en 1853 por Egawa Hidetatsu, del shogunato Tokugawa, para proteger Edo de posibles ataques marítimos (Takatoshi, 2004). Daiba, en japonés, se refiere a la batería de cañones que se instalaron en dichas islas. A finales del siglo $\mathrm{xx}$, toda esa zona sufrió una fuerte expansión para convertirse en una importante zona turística, de ocio, con grandes hoteles y centros comerciales.

Posteriormente, algunas de las grandes compañías japonesas como Fuji Tv (una de las principales emisoras de televisión nipona), cuyo edificio fue creado por el arquitecto y urbanista japonés Kenzo Tange (Tange, 2019), trasladaron su sede a la isla, y la comunicación con la zona mejoró con la conexión de la línea Rinkai a la del ferrocarril JR East en 2002 y la extensión hacia el este de la línea Yurikamome hasta Toyosu en 2006. Esto permitió la instalación del Miraikan, el Museo de la Ciencia y la Tecnología Emergentes de Japón (Watanabe, 2001). 


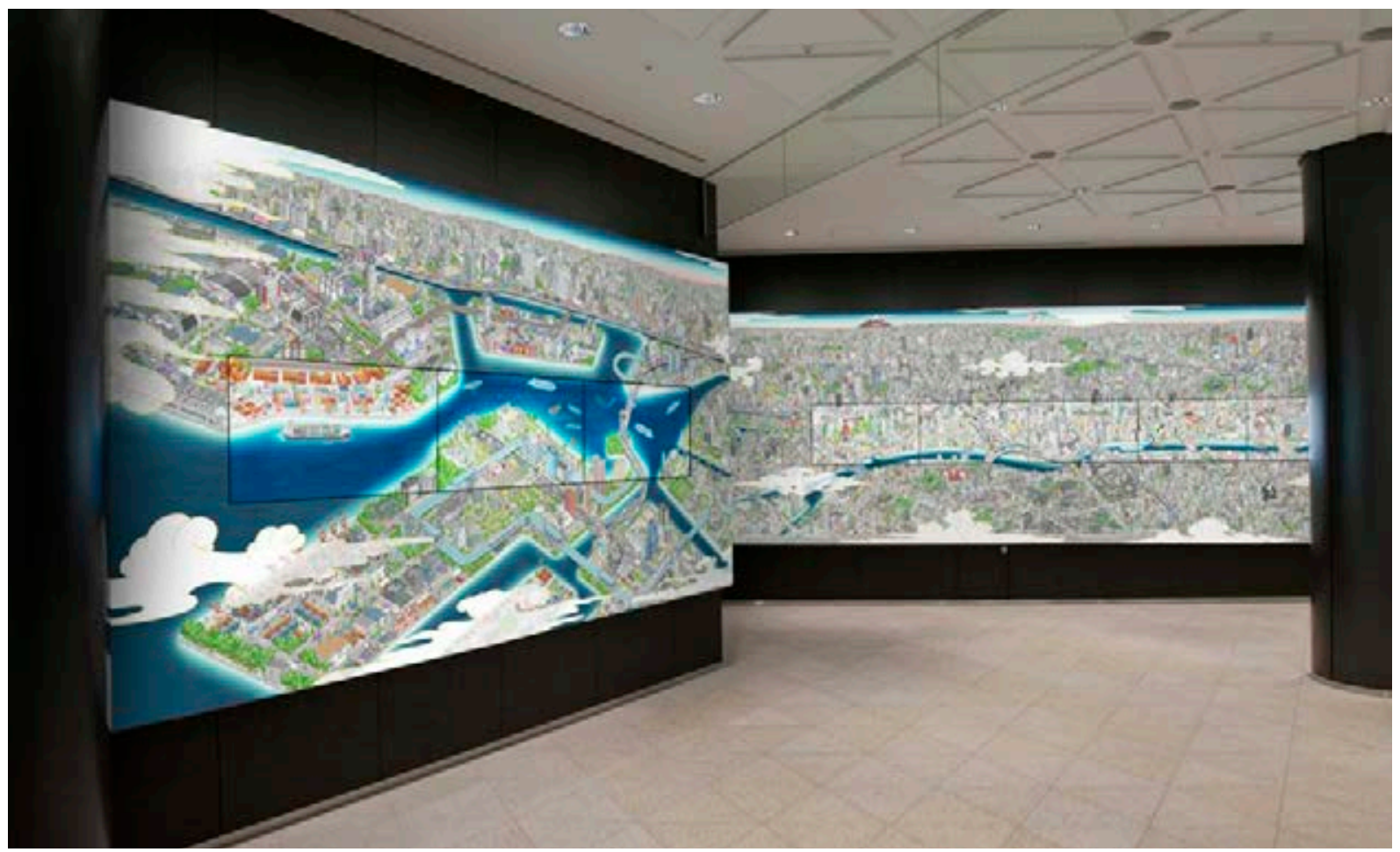

Vista del mural Tokio Skytree. 2012. Fuente: teamLab.art

En cualquier caso, es indudable que la tecnología ha jugado un papel fundamental en la construcción de la identidad japonesa, que siempre ha estado ligada al desarrollo, investigación y uso de las nuevas tecnologías, pero también a la preservación de su cultura tradicional. No obstante, pocas veces se habla de la conexión existente entre esos polos supuestamente opuestos; se suele ignorar el hecho de que una buena parte de las características llamativas de la sociedad japonesa actual encuentra sus raíces en algún aspecto del Japón tradicional (Jansen, 2002). Esa dualidad cultural japonesa es lo que les ha permitido proponer la celebración los próximos Juegos Olímpicos de Tokio 2020 (recordemos, por otra parte, que ya se celebraron también en esta ciudad las Olimpiadas de 1964). En cualquier caso, con el horizonte de 2020 en mente, el colectivo de artistas digitales japoneses líderes a nivel mundial: teamLab, inauguró el pasado 21 de junio de 2018, un museo gestionado de manera conjunta por Mori
Building Co., Ltd, un importante desarrollador de paisajes urbanos (teamLab, 2001).

Debemos señalar que los museos permanentes de arte digital, son, en la actualidad, muy pocos. De ahí la importancia de este primer centro de arte digital permanente que pone de manifiesto que las ventajas de las nuevas tecnologías en el terreno de las industrias culturales son innegables (Liese, 2010: 276).

En el año 2001, el ingeniero Toshiyuki Inoko fundó la sociedad teamLab, que en la actualidad cuenta con unos quinientos empleados procedentes de diversas ramas de la tecnología digital, de las ciencias exactas y del mundo de la creación (teamLab, 2001). Su sede se encuentra domiciliada en la torre Tokio Skytree, en cuyo vestíbulo se puede contemplar un mural digital de unos cuarenta metros de longitud que fue ideado por esta joven empresa, en donde se muestra el skyline animado de la capital de Japón. Esta obra fue el fruto del trabajo de dieciséis artistas gráficos y animadores, y no 


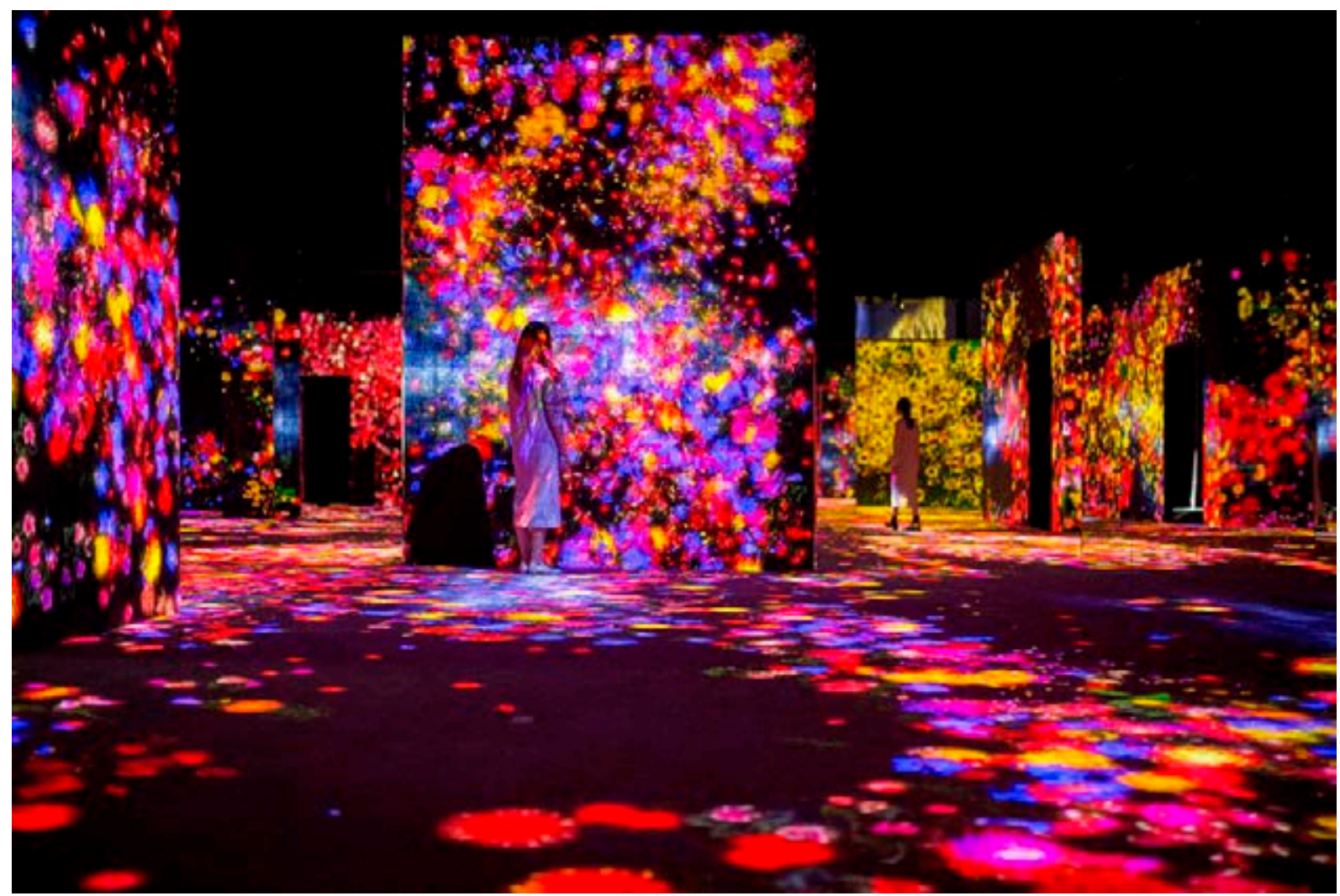

Vista del interior del Mori Building Digital Art Museum: teamLab Borderless, 2018. Fotografía: cortesía de teamLab

tiene un punto de vista central, ya que en los tres estilos del arte tradicional japonés a los que se alude en ella: Ukiyo-e (técnica de grabado en madera muy difundida entre los siglos XVII y xx), Rakuchu-rakugaizu (género de pintura en biombo en la cual se reproducen con todo pormenor escenas de la vida cotidiana de la ciudad de Kioto, antigua capital del Japón) y Edozubyoubu (pintura en biombo en la cual se reproducen escenas de la ciudad de Edo, antiguo nombre de Tokio), se plantean con el mismo grado de importancia en cualquier punto del mural (Barlés y Almazán, 2007).

De esa fusión resulta una obra cautivadora, de monumentales dimensiones, que reproduce una vista aérea de la ciudad de Tokio, en el pasado y en el presente, con toda su profundidad y complejidad y a la que se le ha dado el detalle propio de la Capilla Sixtina de Miguel Ángel en el Vaticano.
Asimismo, y gracias a las distintas muestras que se han podido ver en numerosos espacios artísticos del mundo y que se encuentran en las colecciones de museos y galerías de Sydney, San Francisco, Nueva York, Estambul, Melbourne y Helsinki, entre otras ciudades, se dio a conocer la actividad creativa de este colectivo. Un largo camino desde su primera exposición con la que debutaron en el mundo del arte en 2011, en la galería Kaikai Kiki en Taipei gracias al artista Takashi Murakami (teamLab, 2011). Durante este año 2019, el mecionado colectivo artístico multidisciplinar se ha podido dar a conocer en el mercado del arte español, a través de una exposición en la Fundación Telefónica en Madrid, que estuvo formada por las tres instalaciones: «Black Waves: Lost, Immersed and Reborn», «Flutter of Butterflies, Born from Hands» $\mathrm{y}$ «Enso - Cold Light», que buscaban que el visitante transitase 


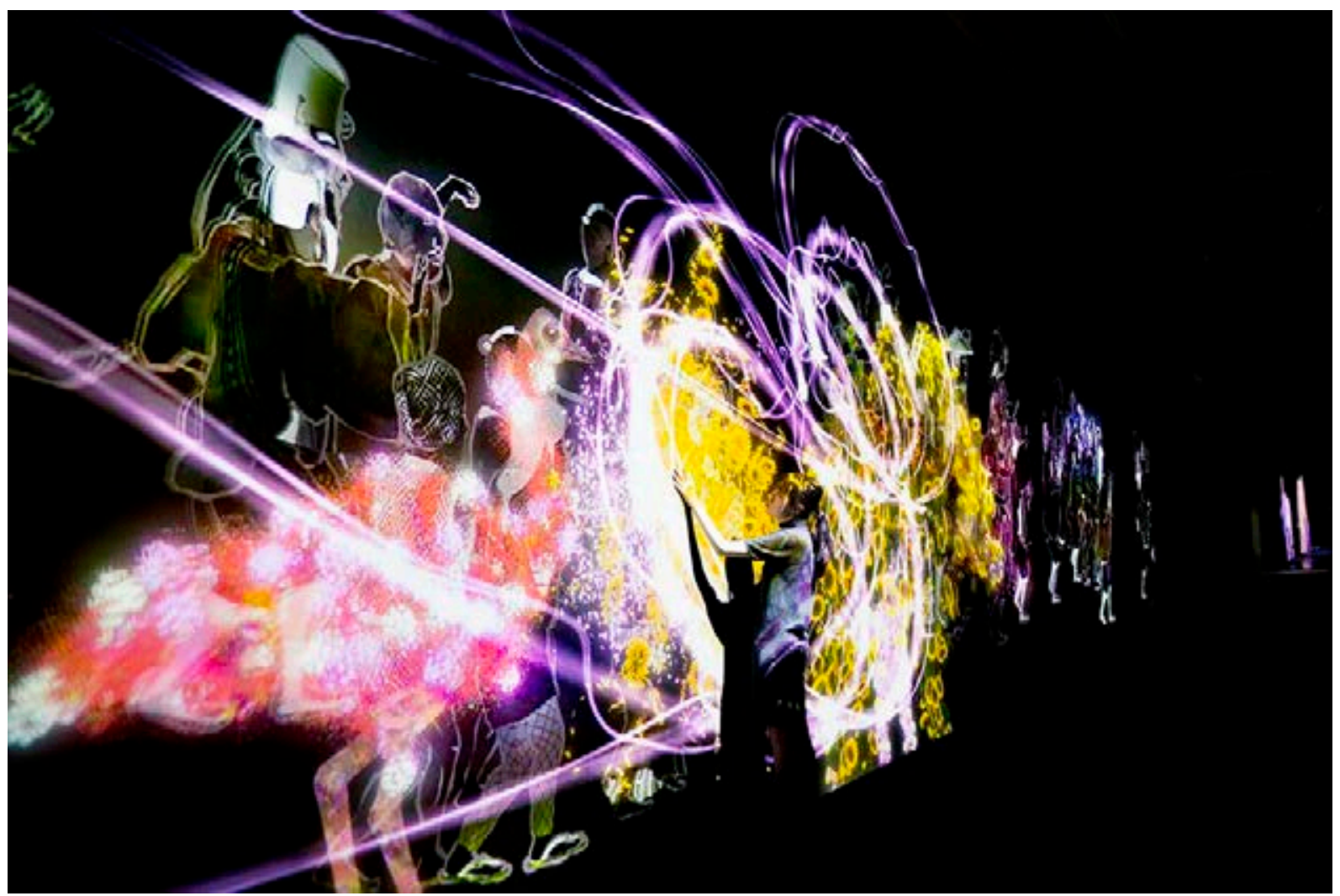

Zona «Borderless World», en el Museo de Arte Digital Mori Building en Tokio, 2018. Fotografía: cortesía de teamLab

a través de ellas, estableciendo relaciones y cambios. De esta forma consiguieron interesar a un público numeroso y traer a nuestro país sus futuristas obras, que exponen la fusión del arte con la informática siendo una fuente constante de sorpresas visuales (Fundación Telefónica, 2019).

A diferencia de las artes tradicionales, una de las facilidades que presenta el arte digital y la tecnología para la producción artística es la posibilidad de experimentar y de modificar constantemente la obra. Es por ello que las obras de arte digital, debido a su carácter inmaterial, no tienen una estructura lineal; son interactivas y en ellas se fusionan diferentes medios y lenguajes. Tal y como estamos viendo, los museos, así como las galerías de arte, han comenzado a abrir sus puertas al mundo digital, aunque de forma cautelosa, pues ese acceso le otorga a la obra digital el aval de "obra museable», es decir, su entrada le da garantía institucional de «obra de arte». Así, algunos centros de arte contemporáneo, como el Guggenheim de Nueva York, ya han exhibido algunas muestras temporales de arte digital. Sin embargo, debemos reconocer que todavía no ha conseguido permiso permanente para franquear las fronteras de los museos de arte contemporáneo. Quizá se deba a su naturaleza de "no coleccionable», a su difícil catalogación, al reto museográfico que supone, o a sus requerimientos tecnológicos específicos para su exhibición (Costa, 1997: 9-13).

Sin embargo, las herramientas digitales pueden constituir un claro aliado a la hora de fomentar la participación de la sociedad civil y la sensibilización en torno a la diversidad de las expresiones culturales. De ahí la importancia de la construcción del Mori Building Digital Art Museum: teamLab 
Borderless. La impresionante y pionera instalación permanente a escala real, cuenta con un total de quinientos veinte ordenadores y cuatrocientos setenta proyectores, repartidos en $10.000 \mathrm{~m}^{2}$ distribuidos en dos plantas, creando un ambiente de pura fantasía. Ese interior se caracteriza por una atmósfera única complicada de definir con palabras, generada gracias al apoyo de varios grupos tecnológicos japoneses importantes desde Panasonic a Epson, que suministran el sofisticado equipamiento que da soporte a las espectaculares instalaciones de arte digital (Mori Building Digital Art Museum, 2018).

Las dos compañías que gestionan este centro han unido fuerzas con el objetivo de marcar un punto de inflexión en la historia del arte, eliminando las fronteras tradicionales, fomentando la interacción con el público, además de proporcionar una gran libertad a los artistas, que pueden aprovechar las ventajas de la nueva era digital para dar rienda suelta a su creatividad. Es un espacio en el que el visitante, cuando accede para observar y disfrutar de las diversas piezas de arte, se encuentra en este caso con unas obras que no son algo físico, no son palpables, sino que son recreaciones digitales dentro de las que se integra el espectador.

Asimismo, debemos aclarar, tal y como indican desde el colectivo artístico, que «las obras no son ni animaciones pregrabadas, ni imágenes en bucle, sino que están realizadas en tiempo real», a diferencia de lo que se puede ver en otras galerías artísticas o exposiciones de arte digital itinerantes, son instalaciones realizadas gracias a la tecnología del videomapping, a través de la cual las piezas reaccionan al movimiento y al tacto, invitando al visitante a formar parte de la escena, en donde la luz y el espacio se convierten en auténticos protagonistas (teamLab, 2018).

El museo se encuentra estructurado en cinco áreas diferentes, para mostrar las aproximada- mente cincuenta obras que se pueden contemplar en su interior, todas a gran escala. En primer lugar, nos encontramos con el espacio denominado «Borderless World», ubicado en la planta inferior, y con el «Athletic Forest», que se sitúa en el piso superior. Además, también podemos contemplar dentro del espacio museístico, la obra «Forest of Lamps», el área infantil denominada «Future Park» y la zona del «Tea House».

El área «Borderless World» (Mundo sin límites), puede considerarse la zona más sensacional del centro de arte. Nada más acceder al interior del edificio, nos encontramos con este espacio, que se caracteriza por tener unos corredores muy oscuros, a través de los cuales se encuentran varias salas y planos abiertos donde se pueden admirar los diferentes montajes, hechos de luces, colores y formas que cambian constantemente y que a menudo interactúan entre sí y con los visitantes, los cuales gracias a la existencia de una aplicación para smartphone pueden influir en el comportamiento de las mismas. De esa forma se consigue invitar al espectador a formar parte de la escena.

Otra característica de esta zona es que no hay mapas o direcciones, sino solo las cartelas en la entrada de cada obra que indican su nombre. Aquí las obras no tienen bordes o marcos que las separen. Según explican sus creadores, «las personas entienden y reconocen el mundo a través de sus cuerpos, de sus sensaciones, moviéndose libremente y formando conexiones $\mathrm{y}$ relaciones con otras personas. Como consecuencia, el cuerpo tiene su propio sentido del tiempo. En la mente, los límites entre distintos pensamientos son ambiguos, lo que causa que se influencien entre ellos y a veces se fusionen. Por ello estas obras de arte tienen el mismo concepto de tiempo que el cuerpo humano» (teamLab, 2018).

Por otro lado, "Athletics Forest» (Bosque atlético), es un ambiente basado en el concepto de entender el mundo a través del cuerpo y pensarlo en su tridimensionalidad. Dos de las obras que 


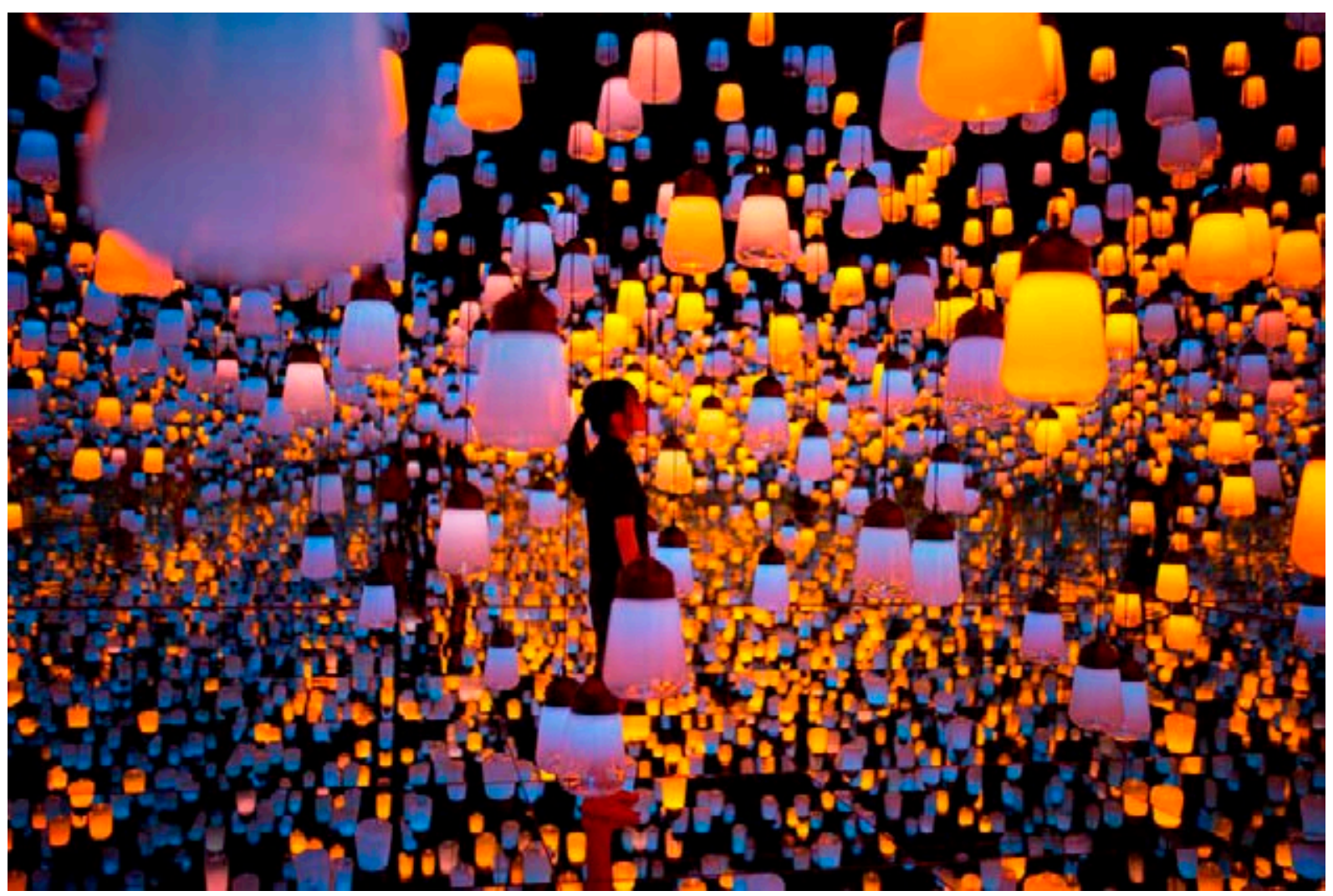

Un miembro japonés de teamLab colectivo camina y posa en una sala de instalación digital con lámparas colgantes, que se iluminan cuando el visitante se acerca y la luz se mueve de una lámpara a otra alrededor de la sala, en el Museo de Arte Digital Mori Building en Tokio, 2018. Fotografía: cortesía de teamLab

más interés han suscitado entre los visitantes han sido: Boing Boing Universe, una especie de cama elástica gigante, y Aereal Climbing, donde se puede simular que uno mismo puede «escalar entre una bandada de pájaros».

En el denominado «Forest of Lamps» (Bosque de lámparas resonantes), otro de los impresionantes espacios del museo, brillan suspendidas desde el techo cientos de lámparas circulares que imitan el impresionante efecto de la ceremonia de los cherry blossom, o lo que se conoce en Japón como Hanami o la llegada del florecimiento de los cerezos, un tradicional evento casi mágico que cada año disfrutan miles de personas en el país nipón y que el centro de arte, de manera digital, ha intentado emular.

Finalmente, el recorrido se cierra con las dos últimas áreas de este centro de arte: la primera
«Future Park» (Parque del futuro), un espacio ubicado cerca de "Athletic World», diseñado principalmente para el público infantil, con el objetivo de estimular su creatividad y cooperación. Las obras más llamativas son Sketch Aquarium, donde los niños pueden dibujar y luego ver sus creaciones en un «acuario» digital, y Sliding through the Fruit Field, un tobogán gigante.

Por su parte, la zona de «Tea House» (Casa de té) ubicada en la planta superior, no es únicamente un lugar para tomar té, sino un verdadero atractivo de este museo. Un espacio donde es posible beberse el arte. Y es que al recibir el té en la taza, este florece generando un mundo de formas y colores dentro del recipiente y lo proyecta alrededor. Eso sí, siempre que quede té. 
En conclusión, en una época en la que la evolución y el desarrollo de la tecnología es abrumadora y que ha conseguido introducirse en la vida de la sociedad actual en todos sus aspectos cotidianos, el colectivo artístico teamLab Borderless ha encontrado lo que parece ser la ecuación casi perfecta entre la confluencia del arte, la ciencia, la tecnología, el diseño y el mundo natural.

Todo ello ha llevado a crear un museo que podría definirse como atípico, sin mapa o recorrido predefinido, en donde se trata más bien de dejar que la curiosidad nos guíe para elegir el camino por el cual comenzar y así conocer las obras que lo componen, obras de arte de instalación digital interactiva que forman un mundo sin fronteras, que salen de las estancias, se comunican con otras obras, influyen $y$, a veces, se entremezclan entre sí e incluso son interactivas, fomentando la participación de los espectadores, para que su presencia cambie el mundo y la concepción del arte actual. De esta forma, el espectador se convierte en un nuevo artista en este espacio co-creativo que pretende crear una experiencia en la que se disuelvan los límites de las obras de arte tradicional, en las cuales, cuando el artista pintaba un lienzo, tenía límites, o, si se creaba una escultura, se modificaba con dificultad. Pero con el arte digital siempre se puede modificar, porque el mundo digital no existe realmente.

Queda claro que son muchas las ventajas de la nueva era digital, pero definitivamente este museo ha creado una oportunidad única para sorprender al visitante con los avances de la tecnología moderna y su aplicación en el ámbito cultural, mediante el cual se está apreciando el arte como nunca se había hecho con anterioridad. Por tanto, podemos decir que el arte digital permite elevar al máximo nivel la expresión "poner el espectador dentro de la imagen», y de hecho esa era la idea que nació en la época de las vanguardias, la de crear la obra de arte total o Gesamtkunstwerk, término acuñado por el compositor de ópera Richard Wagner, quien lo utilizó para referirse a un tipo de obra de arte que integraba las seis artes: la música, la danza, la poesía, la pintura, la escultura y la arquitectura (Sebreli, 2002: 293).

Igualmente, el arte digital responde a una necesidad común: la de maravillar y crear experiencias significativas, enriquecedoras y estimulantes, que nos permitan despertar nuestra creatividad, curiosidad y sentido crítico. De esa forma el arte experimenta una nueva forma de vida.

\section{REFERENCIAS / BIBLIOGRAFÍA}

Barlés BÁguena, Elena y Almazán Tomás, Vicente David (2007) Estampas japonesas: historia del grabado japonés $y$ de su presencia en España, Zaragoza: Fundación CAI-ASC: Fundación Torralba-Fortún.

Barlés BÁguena, Elena y Almazán Tomás, Vicente David (2011) «El mundo actual y Japón desde España», Asociación de Estudios Japoneses en España, Congreso IX, Zaragoza, 13-38.

Bellido Gant , María Luisa (2002) Arte, museos $y$ nuevas tecnologías, Gijón: Trea.

Costa, Mario (1997) «Estética, Técnica, Tecnologías», en Giannetti, Claudia. (Ed.) Arte en la era electrónica: Perspectivas de una nueva estética, Barcelona: ACC L'Angelot y Goethe-Institut, 9-13.

Foster, Hal y Krauss, Rosalind (2006) Arte desde 1900: modernidad, antimodernidad, posmodernidad, Madrid: Akal.

Hooper Greenhill, Eilean (1998) Los museos y sus visitantes, Gijón: Trea.

HuERTA RAMón, Ricard (2011) «Maestros, museos y artes visuales: construyendo un imaginario educativo», Arte, individuo y sociedad, vol. 23, 1, 55-72.

JANSEn, Marius B. (2002) The making of modern Japan, Cambridge, Mass: Belknap Press of Harvard University Press.

Lieser, Wolf (2010) Arte Digital. Nuevos caminos en el arte, H.F. Ullmann Publishing. 


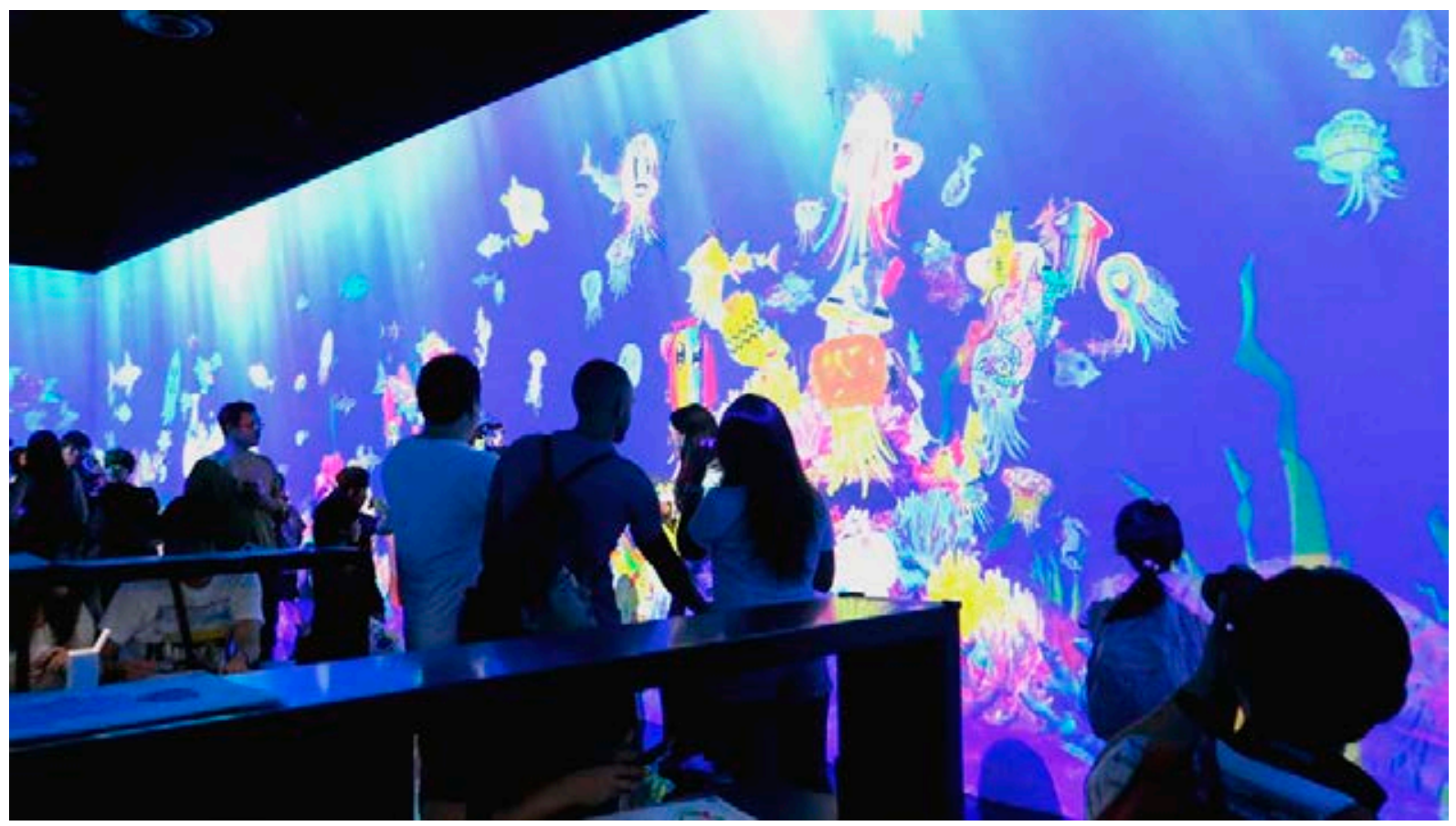

Sketch Aquarium, en el Museo de Arte Digital Mori Building en Tokio, 2018. Fotografía: cortesía de teamLab

Mateos Rusillo, Santos M. (2013) «Museos y Content Marketing. Hacia un nuevo modelo de generación de contenidos culturales», Zer, Revista de Estudios de Comunicación Vol. 18 - 34, UPV, 13-38.

Moreno, Isidro (1997) «Multimedia y museos en España: de prohibido tocar a toque por favor», Cinevídeo 20, 137, 20-29.

Sebreli, Juan José (2002) Las aventuras de la vanguardia, Buenos Aires: Editorial Sudamericana Señales.

TAKekoshi, Yosaburō (2004) The economic aspects of the history of the civilization of Japan, London: George Allen \& Unwin LTD.

WatanaBe, Hiroshi (2001) The architecture of Tokyo: an architectural history in 571 individual, Edition Axel Menges.

\section{Publicaciones online}

Artium, Biblioteca y Centro de Documentación (2013) «Kenzo Tange. Biografía y obra», <http://catalogo. artium.eus/printpdf/book/export/html/7748> [05/08/2019].

ArTvalor, The art investment Company (2018) «Le meraviglie dell' Arte Digitale: apre il primo museo del TeamLab a Tokyo», <https://artvalor.com/it/2018/07/23/ teamlab-digital-art-new-museum-opened-in-tokyo/> [11/08/2019].
Díaz De Quijano, Fernando (2019) «Teamlab: una inmersión en el arte zen digital», <https://elcultural. com/Teamlab-una-inmersion-en-el-arte-zendigital?pdf $=72778>$ [05/08/2019].

FundACIÓN TELEFÓNICA (2019) «EXPOSICIÓN TEAMLAB», <https://espacio.fundaciontelefonica. com/evento/teamlab/> [06/08/2019].

Kulesz, Octavio (2014) «UNESCO Convention on the Protection and Promotion of the Diversity of Cultural Expressions: Analysis of parties' periodic reports and contemporary digital trends», <http:// es.unesco.org/creativity/sites/creativity/files/ sessions/8_igc-inf_5_digital_en.pdf > [05/08/2019].

Miraikan, The National Museum of Emerging SCIENCE AND INNOVATION <HTTPS://WwW. MIRAIKAN.JST.GO.JP/> [05/08/2019].

Mori Building Digital Art Museum: teamlab BORDERLESS <https://borderless.teamlab.art> [08/08/2019].

TEAMLAB <https://www.teamlab.art/> [06/08/2019].

Recibido el 4 del 9 de 2019

Aceptado el 26 del 11 de 2019 BIBLID [2530-1330 (2019): 74-83] 